\title{
Los medios de comunicación y el bicentenario
}

Óscar Aguilar-Bulgarelli *

\section{Resumen}

La independencia surge, en buena parte, gracias a la difusión de las nuevas ideas de la Ilustración; por ello, el surgimiento de la prensa fue vital. En el caso de Centroamérica, los periódicos El Amigo de la Patria y El Editor Constitucional fueron vitales a lo largo del periodo republicano a partir de 1821; sin embargo, cuando la prensa se convirtió en el instrumento de sectores poderosos, manipuladora de la opinión pública a través de la misma opinión publicada, se recibe este bicentenario con una sociedad mediatizada, mediocre y gravemente afectada de un mal muy peligroso: la indiferencia. Especialmente los medios, empresas en manos de los poderosos que además han logrado una enorme concentración de medios de comunicación, los cuales solo permiten publicar, entrevistar u opinar a aquellos que están dentro de su línea de pensamiento único, lo que lleva al ciudadano a una dictadura mediática o tiranía en democracia, como fue llamado en el libro homónimo, en el cual se demuestran, documentalmente, los aspectos señalados, y que en este ensayo ${ }^{1}$ aparecen con la necesaria brevedad.

Palabras clave: libertad, dictadura, manipulación.

* Licenciado en Historia por la Universidad de Costa Rica (1967) y doctor en Filosofía y Letras por la Universidad Complutense de Madrid (1971). Cofundador de la Universidad Nacional (UNA) y de la Universidad Estatal a Distancia (UNED), así como fundador de las editoriales EUNA y EUNED. Catedrático de la Universidad de Costa Rica y de la UNA. Por su labor en el campo académico ha merecido varios premios internacionales, entre los que destacan: Orden de Isabel la Católica (España) y Premio Hermandad de los Pueblos (Argentina). Fundador del Sistema Nacional de Radio y Televisión Cultural (SINART). Diputado a la Asamblea Legislativa en el periodo 1982-1986. Internacionalmente, ha sido presidente del Instituto Panamericano de Geografía e Historia (OEA), director Regional de la Organización Iberoamericana de Seguridad Social (OISS) y académico de Número de las Academias de Geografía e Historia y de Ciencias Genealógicas de Costa Rica, correspondientes de las de México, Guatemala, Honduras, República Dominicana y de la Real Academia de Historia, de España. Es autor de más de 46 libros. En las últimas tres décadas ha estudiado ampliamente el tema de los medios de comunicación en Costa Rica; uno de sus últimos libros, ¿Dictadura mediática o tiranía en democracia?, recibió el premio al Honor y la Ética, del Colegio de Periodistas de Costa Rica. Correo: aguibulg73@gmail.com

\footnotetext{
${ }^{1}$ Aprobado por el comité editorial de la Revista Espiga en sesión del 9 de abril de 2021. La sección en que se publica no es arbitrada mediante el proceso de pares.
} 
El proceso de independencia en Centroamérica, iniciado hace doscientos años, tuvo un soporte fundamental: la prensa. Gracias a que de nuevo, en 1820, se puso en vigencia la Constitución de Cádiz y con ella la libertad de imprenta, surge la posibilidad del libre tránsito de las ideas.

En Guatemala surgen dos periódicos fundamentales: El Editor Constitucional, dirigido por don Pedro Molina, y El Amigo de la Patria, con don José Cecilio del Valle a la cabeza. Ambos, desde posiciones diferentes, abogaban por la libertad; el primero, más radical, luchaba por su obtención inmediata; el segundo, más moderado, consideraba necesario que hubiera un proceso de entendimiento del pueblo de lo que estaba a punto de lograr y así, entonces, pudiera gozar aquel logro con la debida plenitud, conciencia y autoridad.

Pero para ambos, la libertad de imprenta y circulación de las ideas ilustradas era igualmente fundamental. Molina, ya en el primer ejemplar de El Editor Constitucional, decía:

El libre uso de la palabra es como la divisa de un pueblo libre; pues el poder establecer la opinión pública acerca de sus derechos, de donde deben emanar las leyes, es en realidad lo que constituye su soberanía. Sería ésta no más que de un momento si se limitase a la facultad de nombrar sus representantes: el resto de su vida el ciudadano no sería más que un vasallo, o por mejor decir, un esclavo ${ }^{2}$.

Por su parte, don José Cecilio del Valle, en El Amigo de la Patria, proclamaba que:

La imprenta es el sentido universal del cuerpo político, así como el tacto es el sentido general del cuerpo humano. Su libertad es consecuencia necesaria de la falibilidad común. Es preciso permitirla, o decir que los gobiernos no pueden errar. Ella enfurece el espíritu engañoso de dominación, porque le quita la máscara; ella intimida y desconcierta a la audacia y tiranía por la posibilidad sola de su vigilancia; pero esos temores que inspira son elogios serios, y una prueba más de su necesidad ${ }^{3}$.

Por ideas como estas, los dos medios de comunicación se convirtieron en caminos efectivos hacia la libertad, herencia que debe ser reverenciada y bien entendida por los medios de comunicación y la ciudadanía de hoy, en vez de ser mancillada $u$ olvidada, que es peor. Como si aquellas manifestaciones no fueran suficientes sustentar la función de la prensa en una sociedad libre y democrática, años después, el fundador de la República (única que jurídicamente ha existido en nuestra historia) y primer presidente, el Dr. José María Castro Madriz, señalaba:

Quiera Dios que durante mi presidencia sean saciadas las hambres de libertad de prensa (...) Creo que la expresión de la verdad, aún la más amarga, conviene al gobernante que como yo, tiene el valor de abdicar ante ella sus errores, y el sincero deseo de tomarla por base de sus actos ${ }^{4}$.

\footnotetext{
${ }^{2}$ Pedro Molina, El editor constitucional (Ciudad de México: Editorial José de Pineda Ibarra, 1969), 1.

${ }^{3}$ José Cecilio del Valle, El Amigo de la Patria (Ciudad de México: Editorial José de Pineda Ibarra, 1969), 34.

${ }^{4}$ Rafael Obregón Loría, El Dr. José María Castro Madriz: paladín de la libertad y de la cultura (San José: La Nación, 1949), 35.
} 
Admonición válida para los gobernantes de hoy, pero también para los medios que olvidan su labor de verdaderos fiscales de la democracia, para convertirse en celadores del poder político, para cuidar los intereses económicos de la oligarquía que los posee, aunque ello vaya contra la democracia y las mayorías. Sirva de ejemplo las informaciones manipuladas en los principales medios sobre el convenio con el Fondo Monetario Internacional (FMI) y la Unidad Presidencial de Análisis de Datos (UPAD).

Para nadie es un secreto que periódicos como La Nación o noticiarios como Telenoticias han sido los principales voceros de los sectores plutocráticos del país, como se demostró documentalmente en los libros, Costa Rica ¿Dictadura mediática o tiranía en democracia? y Con la patria en el bolsillo. Pero la adhesión de esos medios a la administración Alvarado Quesada ha sido evidente; precisamente la línea editorial de estos medios se ha inclinado clara y definitivamente en favor del convenio con el FMI, a tal punto que los espacios dedicados a las voces pro-convenio son diametralmente opuestos a los que no siguen esa línea de pensamiento. Valga para demostrarlo el simple hecho de que entre el ministro de Hacienda, el presidente ejecutivo del Banco Central (exfuncionario del FMI, casualmente) y el propio presidente de la República han publicado ocho entrevistas a páginas completas $\mathrm{y}$, en algún caso, dos el mismo día, sin que a la contraparte se le haya dado una posibilidad semejante, ni lejanamente.

También, en el caso de la UPAD, el peso informativo lo han llevado fundamentalmente el Diario Extra, CRhoy y el Semanario Universidad; en tanto los medios de la plutocracia, a pesar de la gravedad de este hecho, han sido complacientes, con informaciones «livianas» $\mathrm{y}$ hasta algunos editoriales un tanto evasivos del tema.

¿En qué recodo del camino de la historia patria quedaron perdidas esas ideas fundamentales y propósitos trascendentes? Porque, si bien se pregona a los cuatro vientos la supuesta libertad de expresión que se goza en Costa Rica, mal se haría en vivir de las glorias del pasado y no ver lo que sucede en la actualidad, doscientos años después de los escritos de Molina, Valle o Castro Madriz.

Es cierto que no se ve periodistas encarcelados ni medios de comunicación cerrados por algún gobierno y que algunas diferencias se han resuelto en los tribunales de justicia; pero ¿Basta con ello? Obviamente no, pues la realidad es otra. Se refiere a que en Costa Rica no se vive una dictadura militar de signo alguno ni tiranías al estilo de un Pinochet u Ortega Saavedra; a que todavía hay canales institucionales o legales para llevar a juicio a los medios que se extralimiten como fue el famoso caso de Juan Diego Castro versus La Nación, medio que fue condenado por difamar al abogado acusador; también, hay que señalar cómo muchos periodistas han salido absueltos en los estrados judiciales.

La limitación para dar a conocer el pensamiento de los ciudadanos no viene de un ente gubernamental, sino de los propios medios de comunicación que publican solo lo que va en consonancia con sus intereses políticos o económicos. Tiempo atrás, uno de los articulistas oficiales de La Nación, Eli Feinzaig, en uno de sus artículos oficiales en ese medio, escribió: «Cuando fui INVITADO a escribir en la Página Quince (...)» (el resaltado no es del original). Como dicen los abogados, a confesión 
de partes relevo de pruebas. Para los medios hay dos categorías de ciudadanos: los invitados y $¡$ Los excluidos o jodidos!

Son ellos, poderosos y amorales dueños de medios de comunicación televisivos, radiales o escritos, los que limitan «el libre uso de la palabra» que, como decía Pedro Molina, es necesaria para que haya una verdadera «opinión pública acerca de los derechos» de esos ciudadanos, pues esos poderosos medios, en los que se informa la mayoría de costarricenses, forman la opinión pública manipulada con su opinión publicada, a través de la cual logran, en buena parte, dominar la inteligencia nacional y llegar a la triste realidad de no vivir en democracia, sino en mediocracia, de lo cual tienen una evidente y grave responsabilidad esos medios y un sistema educativo llevado también a esa condición.

El dominio de ese cuarto poder en la democracia, sin ser electo por nadie y generalmente sustentado por el dinero, es mimado por los cortesanos del gobierno institucionalizado para repartirse sus beneficios. Esto no se dice antojadizamente, se pone en evidencia, con muchos ejemplos documentados, en el extenso libro: Costa Rica: ¿Dictadura mediática o tiranía en democracia?

Como bien señala Tzvetan Todorov en Los enemigos intimos de la democracia, los aparentes defensores de la libertad de expresión para su beneficio pasan por alto la diferencia «entre poderosos y no poderosos, lo que les permite echarse flores a sí mismos $»^{5}$.

El peligro es que, ante tal manipulación y dominación mediática que debilita los canales reales de la democracia y la participación ciudadana efectiva, surjan movimientos que, exaltando los sentimientos y necesidades de los sectores olvidados, encabecen movimientos populistas que ofrezcan la solución a las necesidades inmediatas y sentidas.

Como se señaló en el libro Costa Rica: ¿Dictadura mediática o tiranía en democracia?, una de las peores herencias a esta Costa Rica bicentenaria es la enorme concentración de medios de comunicación. Mucho de ese fenómeno se da por la compra de estaciones de televisión y radio por una sola empresa, como es el caso de Repretel, propiedad del mexicano Ángel Remigio González González, quien, desde la sede de su emporio mediático en Miami, maneja decenas de estaciones de radio, televisión y salas de cine en casi toda la América Latina y Estados Unidos. Repretel es dueña, en Costa Rica, de los canales de televisión 2, 4, 6 y 11, más un sistema de televisión por cable y de Central de Radios, que concentra más de diez frecuencias radiofónicas. Es, no dudarlo, el mayor concentrador de frecuencias que hay en el país.

No quiere esto decir que no haya otras empresas igualmente importantes en esa concentración de medios, limitantes de una verdadera libertad de expresión. Son de sobra conocidas y reconocidas las alianzas del Grupo Nación con Prisa de España, que, a su vez, es la propietaria de Grupo Caracol de Colombia, que le permite una serie de importantes enlaces y ser copropietarios de empresas y frecuencias de radio y televisión. Como fresa en ese pastel, está la evidente alianza informativa de $L a$

\footnotetext{
5 Tzvetan Todorov, Los enemigos íntimos de la democracia (Buenos Aires: Del Nuevo Extremo, 2014), 138.
} 
Nación y Teletica, que ha permitido que sus dos «directores dirigidos» hasta tengan un programa conjunto en una emisora del grupo, con el muy apropiado nombre de «Malas Compañías».

Hay otros ejemplos de concentración de medios, pero los aquí señalados, por su poder económico y hasta por tradición o costumbre del costarricense, concentran la mayoría de la audiencia nacional, como es público y notorio, y se señaló reiteradamente en el libro Costa Rica Dictadura Mediática o Tiranía en Democracia. Esto les permite ser contundentes en la formación de la «opinión pública» a través de la «opinión publicada» por dichos medios. Eso, precisamente, es ser también los que seleccionan quiénes y cómo opinan de acuerdo con su línea editorial o lava cocos, es lo que crea la dictadura mediática o tiranía en democracia en Costa Rica.

Es cierto que una adecuada celebración del bicentenario debe permitir la valoración de lo logrado a través de estas dos centurias, pero también los yerros cometidos, pues evidentemente se ha perdido la Costa Rica solidaria a cambio de una egoísta, insolidaria y corrupta. Por ello los medios de comunicación, si quieren actuar con seriedad e inteligencia ( Vaya tarea!), deben tomar la batuta y convertirse en los facilitadores de un escenario para el gran debate sobre el futuro de esta Patria, pero no solo con sus articulistas invitados, acordes con sus líneas editoriales, sino con todos, unos y otros, sin distinciones de ninguna índole; porque sino, muy posiblemente, los nietos de algunos celebrarán el tricentenario ¡Exilados en otras playas!

\section{Formato de citación según APA}

Aguilar-Bulgarelli, Ó. (2021). Los medios de comunicación y el bicentenario. Revista Espiga, 20 (42), 80-85.

Formato de citación según Chicago-Deusto

Aguilar-Bulgarelli, Óscar. «Los medios de comunicación y el bicentenario». Revista Espiga 20, n. ${ }^{\circ} 42$ (setiembre, 2021): 80-85. 


\section{Referencias}

Molina, Pedro. El Editor Constitucional. Ciudad de México: Editorial José de Pineda Ibarra, 1969.

Obregón-Loría, Rafael. Dr. José María Castro Madriz: paladín de la libertad y de la cultura. San José: La Nación, 1949.

Todorov, Tzvetan. Los enemigos intimos de la democracia. Buenos Aires: Del Nuevo Extremo, 2014.

Valle, José Cecilio del. El Amigo de la Patria. Ciudad de México: Editorial José de Pineda Ibarra, 1969. 